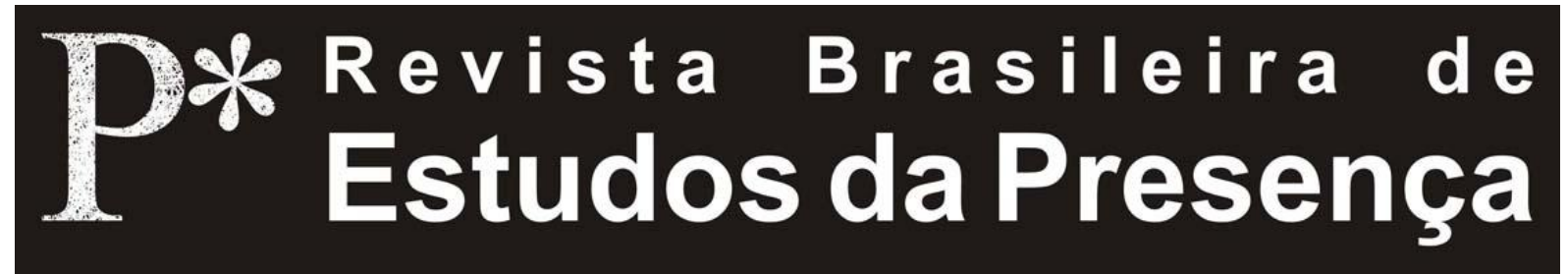

DOI - http://dx.doi.org/10.1590/2237-266022086

ISSN 2237-2660

\title{
Presença em Acontecimentos
}

\author{
Renato Ferracini \\ Ricardo Puccetti \\ Universidade Estadual de Campinas - UNICAMP
}

\begin{abstract}
RESUMO - Presença em Acontecimentos - Este artigo se propõe a uma breve reflexão sobre a questão da presença relacional que se produz na materialidade do encontro poético espetacular. Para isso, traça estratégias para a emergência de um corpo poroso que seja capaz dessa produção e relata experiências concretas disso do que chamamos aqui de presença relacional.
\end{abstract}

Palavras-chave: Presença. Espetáculo. Técnica. Atuação. Memória.

ABSTRACT - Presence in Events - This article proposes a brief reflection on the issue of relational presence that is produced in the materiality of poetic encounter spectacular. For that outlines strategies for the emergence of a porous body that is capable of producing reports and practical experience of what we call relational presence here.

Keywords: Presence. Performance. Technique. Performance. Memory.

RÉSUMÉ - Présence dans les Événements - Cet article propose une brève réflexion sur la question de la présence relationnelle qui est produite dans la matérialité de la rencontre poétique spectaculaire. Pour que les contours des stratégies pour l'émergence d'un corps poreux qui est capable de produire des rapports et une expérience pratique de ce que nous appelons la présence relationnelle ici.

Mots-clés: Présence. Performance. Technique. Performance. Mémoire. 
Este pequeno estudo não pensa a presença do ponto de vista do ator em seu processo de treino ou ensaio. Ele vem, até de forma não acadêmica, falar sobre algumas experiências de presença. Fala sobre aquela presença que se completa com o público. Não uma presença somente centrada no produtor-ator, nem somente localizada na capacidade de afeto do receptáculo-público, mas uma presença-acontecimento-espetáculo que mobiliza os agentes da cena (público e atores) para outros planos poéticos e de experiência. Pensamos aqui em uma presença relacional, que, seguindo a esteira da estética relacional de Bourriaud seria "[...] uma arte [no nosso caso uma presença] que tomaria como horizonte teórico a esfera das interações humanas e seu contexto social, mais que a afirmação de um espaço simbólico autônomo e privado" (Bourriaud, 2006, 13). É nesse contexto que o LUME $^{1}$ busca trabalhar a presença do ator: não como uma potência privada que tem como objetivo chamar a atenção do público, mas como uma certa presença que é produzida por uma porosidade do corpo, uma certa escuta do fora que inclui o outro, o espaço e o tempo na tentativa de estabelecer uma relação de jogo potente e poético. Uma presença da interação poética de múltiplos corpos em relação de potência e diferenciação de si. Uma presença que seria uma materialidade da ação própria do encontro. A questão que se coloca é: como deixar esse corpo poroso e aberto para que essa materialidade do encontro seja possível? Abaixo resumimos algumas estratégias do LUME para essa finalidade de busca de uma presença que se constrói na relação e depois alguns exemplos nos quais, para nós do LUME, essa presença se concretizou.

\section{Na Busca de um Corpo Poroso}

O LUME entende por técnica de ator aquela que consegue esculpir o corpo e as ações físicas no tempo e no espaço, acordando memórias e dinamizando energias potenciais humanas. Através do treinamento cotidiano, o ator, como, artesão que é, se constrói a cada dia, no confronto consigo, com suas forças e fraquezas. Busca sentido naquilo que faz, preenchendo de vida suas ações e 
confrontando a necessidade de, através do trabalho teatral, mergulhar na própria solidão de sua individualidade para encontrar a matéria que vai permitir a construção da ponte entre o ator e os cocriadores que estão na plateia. $O$ Treinamento Energético é a base do trabalho do LUME e vai além das fronteiras do puramente técnico. Trabalhando em ritmo muito rápido e ultrapassando os limites da exaustão física, o ator extravasa ações corporais e sonoras genuínas, repletas de sensações e de emoções muitas vezes contraditórias. $\mathrm{O}$ Energético provoca uma diminuição do lapso de tempo entre um impulso e a concretização de uma ação no espaço. Paralelamente, o Treinamento Técnico amplia a expressividade do corpo e dá forma às energias acordadas no Treinamento Energético. Os elementos técnicos correspondem a exercícios elaborados pelos atores do LUME ou apreendidos e aperfeiçoados de outros grupos e mestres. Com formas e regras de execução bem definidas, os exercícios trabalham com princípios básicos da arte de ator e buscam a precisão, as variações de tamanho e ritmo das ações físicas e vocais, e a construção de um corpo tridimensional. A Dança Pessoal é filha do Treinamento Energético. Com o aprofundamento do trabalho, ações recorrentes e qualidades de energia começam a ser codificadas naturalmente, pela repetição. A memorização permite criar um léxico particular, pessoal e corpóreo do ator. Esses códigos, compostos de dinâmicas físicas e vocais desenhadas no tempo e no espaço, são chamados de matrizes e vão formar $o$ repertório pessoal de cada ator.

Esse é o trabalho em sala em relação ao trabalhotécnica dos atores. Mas o LUME também se preocupa e ativamente age em sua comunidade, não somente na Ação de mostrar seus espetáculos e processos, mas também promover uma transformação social no espaço social onde reside.

Barão Geraldo - Campinas - Brasil é nossa casa. Ou melhor, Barão Geraldo é nossa âncora final, sempre. Viajamos para o mundo, mais de 25 países, e para quase todos os estados do Brasil. Neles sempre levamos nossa casa-arte e construímos fundações fortes. Mas voltar para

Renato Ferracini e Ricardo Puccetti, Presença em Acontecimentos R.bras.est.pres., Porto Alegre, v.1, n.2, p. 360-369, jul./dez., 2011. 
casa, lançar a âncora e respirar mesmos-outros ares sempre foi revigorante. E não estamos sozinhos nesse pequeno distrito de Campinas, que mais parece uma cidadezinha do interior de São Paulo. Ele está muito, extremamente povoado. Fundamos nossa sede em 1994. $\mathrm{Na}$ época somente existia o Sarau do Tucun (Álvaro Tucunduva), ainda de forma improvisada na casa do saudoso e genial Zé Gramani, que morava defronte a nossa sede. Depois Verônica Fabrini, com egressos do curso de artes cênicas da Universidade Estadual de Campinas (Unicamp), formou a Boa Companhia e construiu em sua casa a sede do grupo: Útero de Vênus. O Tucun, do Sarau, deixou de lecionar na Engenharia da Unicamp e montou um teatro no fundo de sua casa e pudemos, então, apreciar shows de música sempre maravilhosos. Logo depois disso, Tiche Vianna e Ésio Magalhães deixaram São Paulo e se instalaram em Barão Geraldo fundando o Barracão Teatro. Lily Curcio e Abel Saavedra nos conheceram, compraram uma chácara e trouxeram o Seres de Luz Teatro. Esses grupos, hoje, têm reconhecimento em todo o Brasil e já ganharam vários prêmios internacionais. E essa proliferação nunca mais parou: outros 15 grupos mais se instalaram em Barão Geraldo. Alguns permanecem, outros já se foram... E nós, em parceria (sempre em parceira), criamos, em 1998, o Tem Cena na Vila I, seguido do II, III, IV e V. Ajudamos a fundar o Feverestival, que hoje caminha com suas próprias pernas: fortes pernas! $\mathrm{E}$ trocamos espaços, equipamentos, técnicas, festas!

Mas o mais importante, para além dessa contaminação no espaço fixo no qual o LUME se encontra, será traçar alguns exemplos dessa presença relacional no campo espetacular. Mostrar, ou ao menos, relatar, essas possíveis experiências de presença relacional. Discorremos agora algumas experiências que a possível força dessa presença construída no acontecimento cênico em espaços urbanos (ou em espaços diferentes do teatro clássico com suas paredes e poltronas) pode proporcionar. 


\section{A Alegria em Alto-mar}

Primeira vez dentro de um helicóptero. Todos nós, malas pessoais, corpos e Parada de Rua apinhados dentro de um deles rumo a uma plataforma de petróleo da Petrobras na Bacia de Campos, no Rio de Janeiro, em 1998. Iríamos participar de um programa interno da empresa pensando no homem off shore, ou seja, nos homens que trabalham nas plataformas. Eles ficam 15 dias em alto mar e 15 dias em casa. O estresse de estar numa zona de perigo constante, longe da família e da terra segura, é grande. Os homens-chefes da Petrobras pensaram que a Parada de Rua do LUME poderia ajudálos. E lá estávamos nós. Ao longe, como um pontinho colorido que se destaca no azul, apareceu aquele monstro de aço que suga da terra coberta por mar aquele líquido preto e viscoso que, depois de processado, faz nossos veículos nos levarem ao cinema. Chegamos, descemos do ser-máquina voador mais barulhento que já andamos e, ao sairmos, abaixamos a cabeça - como fazem nos filmes -, afinal, não queríamos nossos cérebros rolando pela plataforma. Acho que o medo de ser decepado pelas pás em velocidade era tanto que me lembro de alguns de nós até engatinharem de medo. Risos! Mas, sinceramente, não podemos saber se essa lembrança é real, já que muitos anos se passaram e a memória sempre se recria quando as experiências são intensas. E essas foram! Fomos conduzidos por um homem de laranja (aliás, todos os homens lá vestem laranja!) até um lugar para recebermos as instruções de segurança. Instrução um: Caso vocês ouçam uma sirene é porque gases venenosos escaparam e vocês terão que usar essa máscara dentro de 15 segundos, se não há o perigo iminente de morte! Andem sempre com ela por todos os lugares que vocês forem. Inclusive durante o espetáculo? Por todos os lugares! Mas mesmo durante o espetáculo?! POR TODOS OS LUGARES! Sim, depois dessa voz enfática acho que entendemos. Instrução dois: Caso vocês ouçam outra sirene é porque a plataforma está em chamas e vocês devem seguir as rotas de fuga. E lá fomos nós pela rota de fuga. E ficou bastante claro que, se a plataforma pegasse fogo, somente o Minotauro poderia se salvar, 
pois a tal rota era um verdadeiro labirinto. Mas não se preocupem, pois alguém os conduzirá! Ficamos mais tranquilos. Instrução três: Durante o espetáculo vocês não podem ir para a zona de descanso, pois os homens do período noturno estão descansando. Claro! Jamais gostaríamos de perturbar o sono deles. Afinal, eles eram os responsáveis por fazer nossos carros nos levarem ao cinema! E fizemos a Parada! E uma alegria passou a reinar na plataforma. $\mathrm{E}$ os homens dançavam e pulavam conosco. E o chefão - aquele que proibiu a gente de entrar na zona de descanso - foi na nossa frente e nos conduziu diretamente pra dentro dela. E ele - o próprio chefe!!!! - gritava e batia nas portas para acordar os homens que nos levam ao cinema. E eles pulavam da cama e sorriam e participavam da festa. E nem lembramos mais das máscaras de gás penduradas no figurino. Foram muitas plataformas e nem sabemos exatamente se foram sete, oito ou nove. Em todas: instruções, perigos, alegria e Parada de rua. Éramos off shore com eles, como eles e em função deles. Tanto que, nas últimas plataformas, já saíamos do helicóptero correndo, quase eretos e perguntávamos: Onde estão as máscaras de gás? E onde é a zona de descanso? Começaremos por lá! ${ }^{2}$.

\section{Entre Árabes e Israelenses}

Foi difícil entrar em Israel. Desmontaram o acordeão e a clarineta. Duas horas ao todo na fronteira. Pelo histórico do país e de seu povo é fácil entender esse procedimento. Era 1998 e estávamos chegando do Egito, após a participação no festival internacional do Cairo, e cruzamos a fronteira via terra, vindos do deserto do Sinai, onde dormimos na Gruta do Diabo e subimos o Monte Sinai, onde um dos atores, já no topo, caiu num poço (Renato). Ou seja, prestamos homenagem a todas as entidades sem qualquer tipo de moralismo. Enfim, entramos. E lá dentro de Israel nos apresentamos em vários kibutzim. E fizemos a Parada de rua para esses trabalhadores coletivos. Lugares mágicos, nos quais a utopia da coletividade e da socialização do trabalho ainda sobrevive. Lá dentro nada poderia ser desperdiçado no 
almoço e no jantar. Nenhum alimento deveria ser jogado fora. Isso fez com que, por um erro de interpretação, um dos atores tivesse que comer um prato inteiro de macarrão com pudim de chocolate (Renato). Mas o ideal do não desperdício não foi maculado. No dia de folga boiamos no Mar Morto, menos o ator que estava ralado porque havia caído no poço do Monte Sinai (Renato). Tão salgado que você não afunda. Mas um lugar foi verticalmente especial para nós: Neve Shalom. Ali árabes e israelenses não somente convivem, mas aprendem juntos, festejam juntos, cantam juntos, dançam juntos, falam árabe e hebraico juntos. Crianças árabes e israelenses brincam juntas no jardim. E a Parada de rua brincou junto delas. Uma honra apresentar em um lugar de construção de paz e amor. Recebemos mais que doamos. Quase como sempre.... ${ }^{3}$.

\section{Na Praça dos Punks}

A Parada de Rua é um dos espetáculos que mais nos trouxe acontecimentos peculiares, encontros inesperados com público e situações inusitadas. Ela pode ser feita em qualquer lugar, para muita gente. Eu me lembro das sete apresentações no Festival Internacional de Teatro Palco \& Rua, em Belo Horizonte, em 2000. O FIT disse que não gostaria de divulgar a Parada, ao contrário da maioria das vezes em que boa parte do público vai para uma praça ver o espetáculo. A ideia era pegar o público completamente desprevenido, as pessoas que frequentavam os espaços que não aquele do festival. O Festival também não queria pedir autorização para as apresentações e iria nos levar para espaços possíveis de darem confusão. Topamos a ideia: 'tudo bem, mas vocês vão ter que deixar na nossa mão e nós nos viramos com os incidentes'. Gostaria de citar três dessas apresentações. Uma delas foi no Mercado Municipal, em que é proibido fazer qualquer coisa. Começamos na rua e fomos para uma das portas. Quando começou o agito, a segurança ficou ouriçada e barrou as portas formando um paredão de guardas, com pernas abertas e braços cruzados. Fizemos uma provocação muito grande porque eu chegava a quase encostar o meu nariz no do guarda. Eles

Renato Ferracini e Ricardo Puccetti, Presença em Acontecimentos

R.bras.est.pres., Porto Alegre, v.1, n.2, p. 360-369, jul./dez., 2011.

Disponível em http://www.seer.ufrgs.br/presenca 
se seguravam para não descer o cassetete. Foi aglomerando gente do Centro de Belo Horizonte. Como a Parada se desloca, às vezes a gente ia para a outra porta e a segurança corria para lá e, quando eles estavam no meio do caminho, eu, como líder de banda, mudava de direção e conduzia o espetáculo para a primeira porta. Os guardas começaram a disfarçar a risada, enquanto a Parada adquiria um tom político, com gente gritando 'abaixo a repressão'.

Quando fomos embora, a multidão continuou nos seguindo e a apresentação não terminava, porque não tínhamos para onde fugir. Acabou o espetáculo e começamos a cantar e a tocar outras músicas do nosso repertório. Acabou o repertório e veio um senhor com sua esposa falar que naquele dia completavam 25 anos de casados e o espetáculo era um grande presente. Cantamos 'parabéns' para o casal junto com o público. Depois as pessoas cantaram para nós.

No Bar Maleta, que fica no pátio de um prédio, com uma entrada estreita fechada por uma porta de vidro, também foi tenso. A Parada começou na rua e, quando fomos subir a rampa do corredor que dava acesso ao bar, os funcionários fecharam a porta. Só que esse bar fica perto de uma avenida com uma praça onde se reúnem os punks de Belo Horizonte. Eles estavam seguindo o espetáculo. Quando impediram a nossa entrada, os punks encontraram motivo para extravasar a revolta. Ficamos prensados na porta de vidro e os punks querendo derrubar a porta. Pensei, 'eu tenho de manejar esse pessoal, não podemos deixá-los derrubar a porta'. Dei meia-volta, desci a rampa e parei o trânsito da avenida de duas mãos. Era uma das avenidas mais importantes da cidade. O público entrou na avenida e os punks ficaram na maior alegria. Ficamos uns 30 minutos ali, com o pessoal do FIT desesperado para que liberássemos a avenida. Ônibus e carros buzinando, alguns curtindo o espetáculo e outros furiosos. Terminamos o espetáculo na praça dos punks, com todos dançando.

Aprendemos que a Parada move coisas fortes no público e que temos de saber lidar com isso, porque nem sempre são sentimentos leves e alegres. No Parque 
Municipal foi muito engraçado. Lá tem barquinhos no lago. Pensamos que seria lindo encerrarmos a Parada nos barquinhos, indo embora tocando e a multidão na margem vendo a gente sumir no lago. Um final de Fellini! Juntou muita gente e quando estávamos na última música, 'Sanfoninha de ouro', chegamos ao porto e nos dividimos, sendo quatro em um barquinho e três em outro. No meio do lago, os barquinhos começaram a encher d'água e a afundar porque tinha gente demais. Tivemos de voltar e recomeçar a Parada em terra firme para ir embora. Quase que sumimos no lago, um final de filme-catástrofe. Neste dia, veio um gari que trabalha no parque e falou 'eu nunca tinha visto teatro porque sempre achei que fosse uma bobagem, mas isso foi a coisa mais linda que eu vi na minha vida ${ }^{4}$.

\footnotetext{
Notas

1 O LUME Teatro foi fundado em 1985 e hoje é reconhecido em 26 países por ser considerado um dos mais importantes centros de pesquisa teatral do Brasil. Como núcleo artístico e pedagógico vinculado à Universidade Estadual de Campinas (UNICAMP) trabalha na elaboração de novas possibilidades expressivas corpóreas e vocais de atuação, redimensionando o teatro como ofício e poética. Atualmente o grupo, formado por sete atores, difunde sua arte e metodologia por meio de oficinas, demonstrações de trabalho e projetos de intercâmbio e constrói espetáculos que quebram as formas convencionais de relação com o público.

${ }^{2}$ Citado por Renato Ferracini.

${ }^{3}$ Citado por Renato Ferracini.

${ }^{4}$ Citado por Ricardo Puccetti.
}

\section{Referências}

BOURRIAUD, Nicolas. Estética Relacional. Buenos Aires: Adriana Hidalgo Editora, 2006. 
Renato Ferracini é doutor em Multimeios pela UNICAMP. É ator-pesquisador e atualmente Coordenador Acadêmico do LUME onde atua teórica/praticamente em todas as linhas de pesquisa do núcleo desde o ano de 1993. É professor e orientador no Programa de Pós-Graduação em Artes da Cena - UNICAMP. Atualmente coordena o Projeto Temático FAPESP "Memória(s) e Micropercepção" e é Bolsista de Produtividade do CNPQ. É autor de A Arte de Não Interpretar como Poesia Corpórea do Ator (Editora da UNICAMP e FAPESP), Café com Queijo: Corpos em Criação (HUCITEC e FAPESP) e Corpos em Fuga, Corpos em Arte - ORG (HUCITEC e FAPESP - 2006).

E-mail: renato@lumeteatro.com.br

Ricardo Puccetti é ator, palhaço, pesquisador, orientador de atores e diretor. É membro do LUME desde 1988, ajudando a constituir o grupo como núcleo de pesquisa ao lado de Luís Otávio Burnier e Carlos Simioni. É Coordenador Artístico do LUME, membro do Conselho Editorial da Revista do LUME e do Conselho Científico do grupo. Referência internacional na arte do palhaço, responde pela sistematização da pesquisa do LUME na utilização cômica do corpo, desenvolvendo uma metodologia própria de trabalho.

E-mail: ricardo@lumeteatro.com.br

Recebido em Agosto de 2011

Aprovado em Outubro de 2011

Renato Ferracini e Ricardo Puccetti, Presença em Acontecimentos

R.bras.est.pres., Porto Alegre, v.1, n.2, p. 360-369, jul./dez., 2011.

Disponível em http://www.seer.ufrgs.br/presenca 